\title{
The roller coaster flight strategy of bar-headed geese conserves energy during Himalayan migrations
}

\author{
C. M. Bishop, ${ }^{1 *} \ddagger$ R. J. Spivey, ${ }^{1 *}$ L. A. Hawkes,${ }^{1} \dagger \ddagger$ N. Batbayar, ${ }^{2}$ B. Chua,${ }^{3}$ \\ P. B. Frappell, ${ }^{4}$ W. K. Milsom, ${ }^{3}$ T. Natsagdorj, ${ }^{5}$ S. H. Newman, ${ }^{6}$ G. R. Scott, ${ }^{7}$ \\ J. Y. Takekawa, ${ }^{8}$ M. Wikelski, ${ }^{9,10}$ P. J. Butler ${ }^{11}$
}

The physiological and biomechanical requirements of flight at high altitude have been the subject of much interest. Here, we uncover a steep relation between heart rate and wingbeat frequency (raised to the exponent 3.5) and estimated metabolic power and wingbeat frequency (exponent 7) of migratory bar-headed geese. Flight costs increase more rapidly than anticipated as air density declines, which overturns prevailing expectations that this species should maintain high-altitude flight when traversing the Himalayas. Instead, a "roller coaster" strategy, of tracking the underlying terrain and discarding large altitude gains only to recoup them later in the flight with occasional benefits from orographic lift, is shown to be energetically advantageous for flights over the Himalayas.

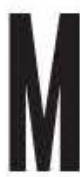

igrating birds must overcome many chal lenging environmental obstacles, such as arid deserts $(1,2)$ and featureless oceans (3 5), but few are capable of negotiating the formidably high mountains separat ing the Indian subcontinent from central Asia. Famously, one species that manages this feat is the bar headed goose (Anser indicus), which bi

School of Biological Sciences, Bangor University, Bangor. Gwynedd, UK. 'Wildlife Science and Conservation Center of Mongolia, Ulaanbataar, Mongolia. ${ }^{3}$ Department of Zoology. University of British Codumbia, Vancouver, British Columbia Canada ${ }^{4}$ Office of the Dean of Graduate Research, University of Tasmania, Tasmania, Australia. ${ }^{5}$ Mongolian Acaderny of Sciences, Ulaanbataar, Mongolia. ${ }^{6}$ Emergency Prevention System (EMPRES) Wildlife and Ecology Unit, Food and Agriculture Organization of the United Nations (FAO), Rome, Italy. 'Department of Biology, McMaster University, Ontario, Ontario, Canada ${ }^{8}$ San Francisco Bay Estuary Field Station, Western Ecological Research Center, U.S. Geological Survey. Vallejo, CA 94592 USA. ${ }^{9}$ Max Planck Institüt für Omithologie, Radolfzell, Germany. ${ }^{10}$ Department of Biology, University of Konstanz, Konstanz, Germany. "School of Biosciences, University of Birmingham, Birmingham, UK.

These authors contributed equally to this work. †Present address: Centre for Ecology and Conservation, University of Exeter. Cornwall Campus, UK. ‡Corresponding author. E mail: c.bishop@bangor. ac.uk (C.M.B.); t.hawkes@exeter.ac.uk (L.A.H.) annually traverses the high passes of the Tibetan massif and snow capped Himalayan mountains $(68)$. Over the years, there has been much de bate as to how high these birds might fly and what physiological mechanisms could be in volved at the highest altitudes $(812)$, but, al though one goose has been directly tracked as high as $7290 \mathrm{~m}$ for a brief period (12), no mea surements of their physiological or biome chanical flight performance have been made in the wild.

To investigate the flight dynamics and ener getics of migratory bar headed geese, we used custom designed implantable instruments (13) to measure abdominal temperature and pres sure (every $30 \mathrm{~s})$, tri axial acceleration $(100 \mathrm{~Hz}$ in $18 \mathrm{~s}$ bursts every $2 \mathrm{~min}$ ), and electrocardio graphy ( $180 \mathrm{~Hz}$ in the same $18 \mathrm{~s}$ period) from seven birds, collecting data totaling 391 hours of migratory flight (Fig. 1). The data loggers weighed $32 \mathrm{~g}$ and were housed in biocompat ible tubing (dimensions $7 \times 2 \mathrm{~cm}$ ) capped by titanium electrodes.

Abdominal body temperature during flight $\left(40.2^{\circ} \mathrm{C}+1.2 \mathrm{SD}\right)$ tended to increase in tandem with flight activity, especially during times of 
intense effort (Fig. 1) but was generally insensitive to changes in altitude (fig. S1). The frequency distribution of all pressure determined altitude measurements recorded during the migratory flights is shown in Fig. 2A. The median altitude while traversing the Tibetan plateau was $4707 \mathrm{~m}$ (maximum $6443 \mathrm{~m}, 90 \%$ of observations $5600 \mathrm{~m}$ ). Thus, pressure derived altitudes do not pro vide evidence for a general paradigm of extreme high altitude $(>8000 \mathrm{~m}$ ) migratory flight in this species (12).

In order to estimate rate of oxygen consump tion $\left(\dot{V}_{\mathrm{O}_{2}}, \mathrm{ml} \mathrm{min}^{-1}\right)$ during flight from mea sures of heart rate $\left(f_{\mathrm{b}}\right.$, beats $\left.\mathrm{min}^{-1}\right)(14 \mathrm{17})$, we apply an allometric proportionality derived for 12 species of birds during flight (14) to data ob tained from bar headed geese flying in a wind tunnel (17) (fig. S2), and obtain the calibration relationship:

$$
\dot{V}_{\mathrm{O}_{2}} \quad 0.07 \pm 0.002 M_{\mathrm{b}}^{0.24 \pm 0.01} M_{\mathrm{h}} f_{\mathrm{h}}^{2}
$$

For wild migratory geese, we substitute values for body mass $\left(M_{\mathrm{b}}\right)$ of $2.8 \mathrm{~kg}$ and heart mass $\left(M_{\mathrm{h}}\right)$ of $1 \%$ of body mass $(18)$. We then con verted estimates of $\dot{V}_{\mathrm{O}_{2}}$ to estimates of meta bolic flight power $\left(P_{\mathrm{m}}, \mathrm{W} \mathrm{kg}{ }^{-1}\right)$ by assuming $1 \mathrm{ml} \mathrm{O}_{2} \cong 20.9 \mathrm{~J}$. Additionally, we estimate bio mechanical body power $\left(P_{\mathrm{b}}, \mathrm{W} \mathrm{kg}^{-1}\right)$ during flight, using measures of dynamic body ac celeration (1922). Here, we show that a single $P_{\mathrm{b}}$ component is dominant when empirically cor relating several theoretical terms (22) for $P_{\mathrm{b}}$ against our estimates of $P_{\mathrm{m}}$, which determines that time averaged body power during the flapping flight of geese could be predicted by

$$
P_{\mathrm{b}} \quad \frac{\ddot{Z}_{\mathrm{rms}}^{2}}{2 \mathrm{p}^{2} f_{\mathrm{w}}}
$$

where $\ddot{Z}_{\mathrm{ms}}^{2}$ is root mean square dorsoventral acceleration ( $z$ axis) and $f_{\mathrm{w}}$ is wingbeat frequency.
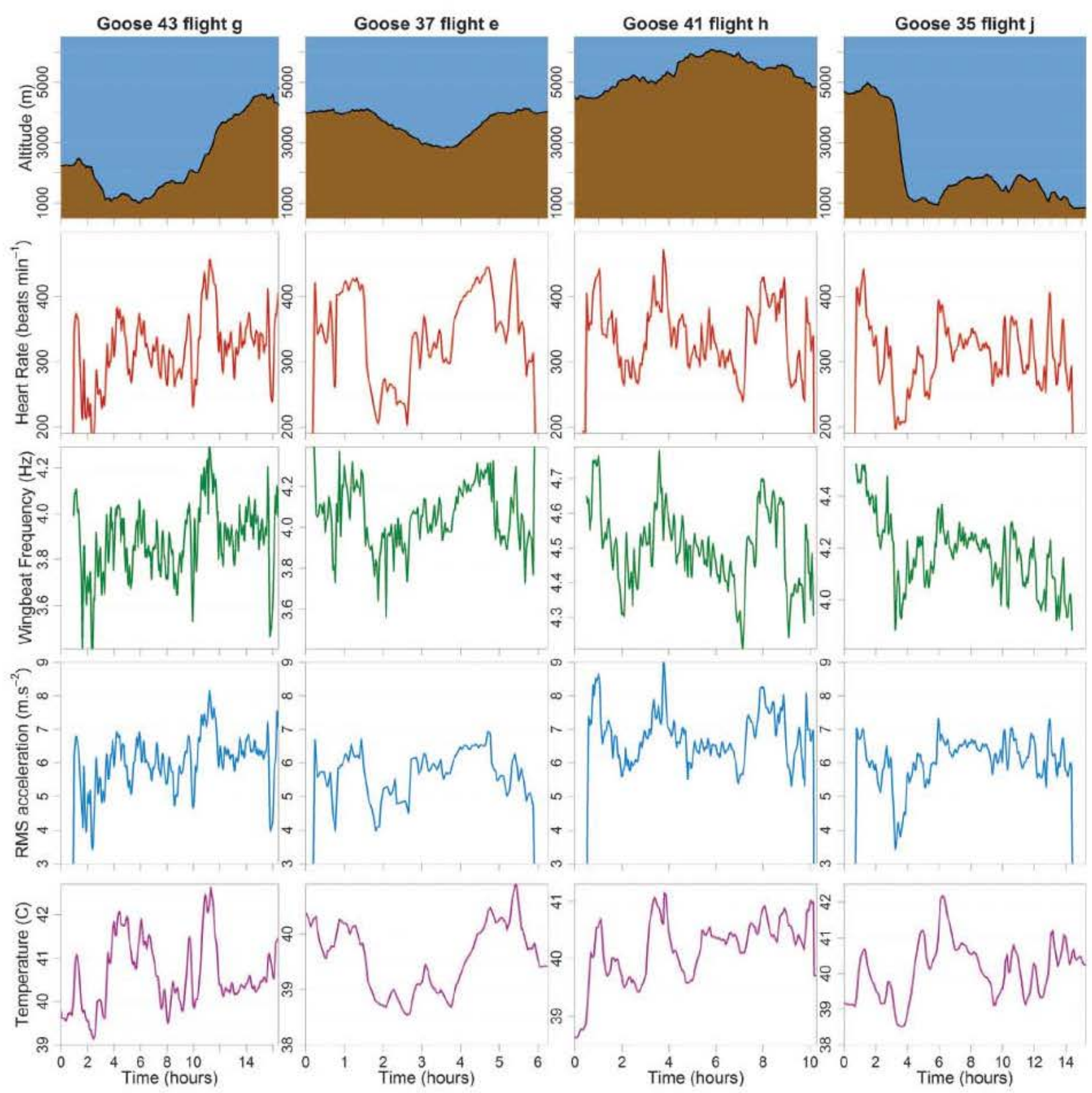

Fig. 1. Examples of autumn migratory flights. Bar-headed goose (Anser indicus) P43 travelled South from Mongolia and ascended onto the Tibetan Plateau (column 1); goose P37 (column 2) and goose P41 (column 3) were traversing the Tibetan Plateau; goose P35 (column 4) crossed the Himalayas and descended into India. Pressure altitude (row 1), $f_{\mathrm{h}}$ (row 2), $f_{\mathrm{w}}$ (row 3 ), $\ddot{\mathrm{Z}}_{\mathrm{rms}}^{2}$ (row 4), abdominal body temperature (row 5). 
This simple term maximized correlations be tween the independently derived biomechanical $P_{\mathrm{b}}$ and metabolic $P_{\mathrm{m}}\left(\right.$ mean $\left.r^{2}=0.91+0.05 \mathrm{SD}\right)$ (Fig. 2B).

During flight, heart rate and wingbeat fre quency were significantly correlated (mean $r^{2}>$ $0.86+0.11 \mathrm{SD}$ ) (Fig. 2, C and D, and fig. S3A), as well as heart rate and $\ddot{Z}_{\text {ms }}^{2}$ (mean $r^{2}=0.91+$ $0.05 \mathrm{SD}$ ) (Fig. 2C and fig. S3B) and wingbeat frequency and $\ddot{Z}_{\text {ms }}^{2}$ (mean $r^{2}=0.89+0.09 \mathrm{SD}$ ) (fig. S3C). Median wingbeat frequency increased with pressure derived altitude as air density de clined (median $f_{\mathrm{w}}=3.94 \mathrm{~Hz}$ at altitude $<2300 \mathrm{~m}$; $f_{\mathrm{w}}=4.35 \mathrm{~Hz}$ at altitude $>4800 \mathrm{~m}$ ) (Fig. 2E). Similarly, median heart rate during flight in creased with altitude and was generally higher on the Tibetan plateau $\left(f_{\mathrm{h}}=364\right.$ beats $\min ^{-1}$ at altitude $>4800 \mathrm{~m}$ ) (Fig. 2F) than at lower al titudes $\left(f_{\mathrm{h}}=300\right.$ beats $\mathrm{min}^{-1}$ at altitude $<2300 \mathrm{~m}$ ). Although the partial pressure of oxygen de creases with increasing altitude, up to around
$5000 \mathrm{~m}$, any potential desaturation of oxygen bound hemoglobin in the blood of bar headed geese should still be relatively small, at around $10 \%(18,23)$. Indeed, captive bar headed geese are able to run for $15 \mathrm{~min}$ at similar maximum speeds, whether exposed to atmospheres of 21, 10.5 , or $7 \%$ oxygen, the last mentioned condi tion resulting in a desaturation of between 20 and $23 \%(18)$.

Our data show that median heart rate during flight scales with air density $(\rho)$ as $f_{\mathrm{h}} \propto \rho^{-0.64}$ (Fig. 2G) and, therefore, that estimated $P_{\mathrm{m}}$ should scale approximately as $P_{\mathrm{m}} \propto \rho^{-0.91}$ (if one assumes that $P_{\mathrm{m}} \propto f_{\mathrm{h}}^{2}$ but allowing for a $10 \%$ additional increase of $f_{\mathrm{h}}$ for a given value of $\dot{V}_{\mathrm{O}_{2}}$ at $5500 \mathrm{~m}$ due to a hemoglobin de saturation of $10 \%$ ). Thus, the relative metabolic flight power of the geese at $5000 \mathrm{~m}$ compared with that at sea level is estimated to be around 1.7 fold. This is higher than the anticipated sen sitivity of flight power to air density of $P_{\mathrm{m}} \propto \rho^{-0.54}$ predicted by aerodynamic theory (24). Similar ly, flight theory predicts that wingbeat frequency should be $\propto \rho^{-0.38}$, whereas the present results for bar headed geese show median $f_{\mathrm{w}} \propto p^{-0.23}$ (Fig. 2H). This is at the lower end of the pre dicted range but in keeping with the observa tions of large Ciconiiformes (herons, spoonbill, ibis) migrating high above the Negev Desert in Israel (25).

Bar headed geese exhibit an extreme sensitiv ity of heart rate and, therefore, metabolic flight power to small changes in wingbeat frequency, when a precise method is used for extracting values of $f_{\mathrm{w}}(26)$. For example, a $5 \%$ increase in $f_{\mathrm{w}}$ from 4.0 to $4.2 \mathrm{~Hz}$ equates to a $19 \%$ increase in $f_{\mathrm{h}}$ and, therefore, a $41 \%$ increase in estimated $P_{\mathrm{m}}$. Across all migratory flights, $f_{\mathrm{h}}$ correlated in the range of $f_{\mathrm{h}} \propto f_{\mathrm{w}}{ }^{195}$ to 6.65 and estimated $P_{\mathrm{m}}$ as $P_{\mathrm{m}} \propto f_{\mathrm{w}}{ }^{3.9}$ to 13.3 , the latter exponent ex ceeding 3 in every case (median exponent 6.96) (Fig. 2I). For steady horizontal flight, the inertial
Fig. 2. Descriptive flight statistics. Frequency histograms of (A) altitude reported during migratory flights of bar-headed geese (Anser indicus) and $(B)$ correlation of estimated $P_{\mathrm{m}}$ versus estimated $P_{\mathrm{b}}$. (C) Correlation of $f_{\mathrm{h}}$ versus $f_{\mathrm{w}}$ plotted against correlation of $\ddot{Z}_{\text {rms }}^{2}$ versus $f_{\mathrm{wr}}$ (D) Examples of $f_{\mathrm{h}}$ against $f_{w}$ for four individual flights. Frequency distribution of (E) $f_{\mathrm{w}}$ and $(\mathbf{F}) f_{\mathrm{h}}$ within three altitude zones. Scatter plots of $(\mathbf{G}) f_{\mathrm{h}}$ and $(\mathbf{H}) f_{\mathrm{w}}$ plotted against altitude. (I) Frequency distribution of power exponents for $f_{\mathrm{w}}$ against estimated $P_{\mathrm{m}}$.
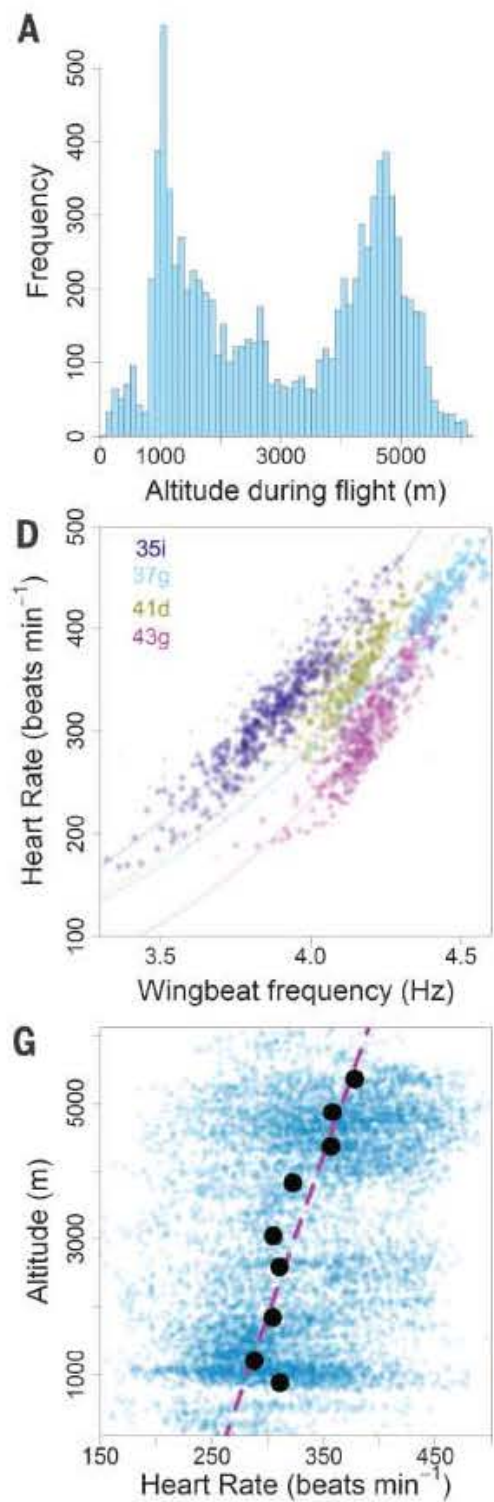
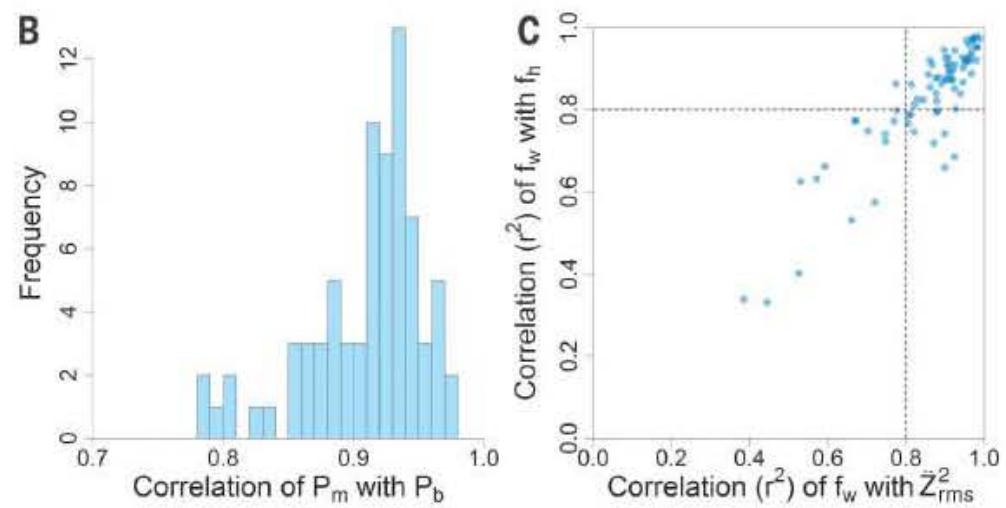

E

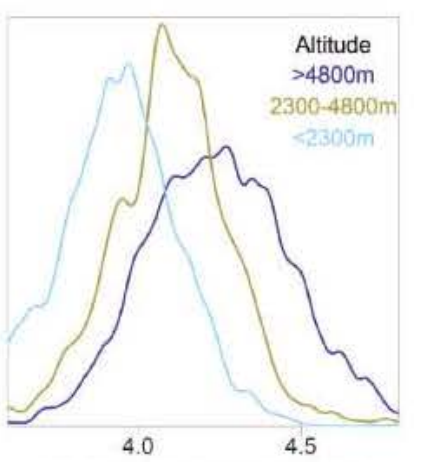

Wingbeat Frequency $(\mathrm{Hz})$

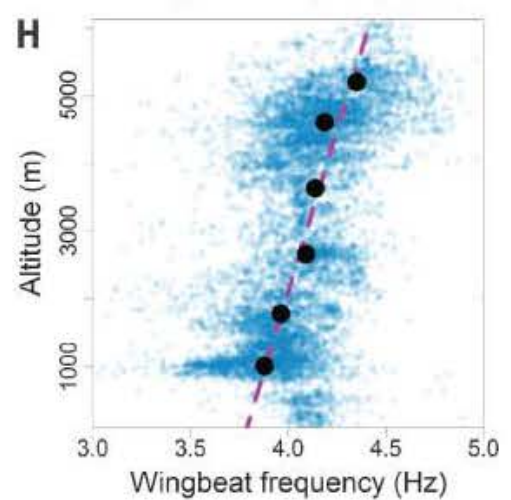

F

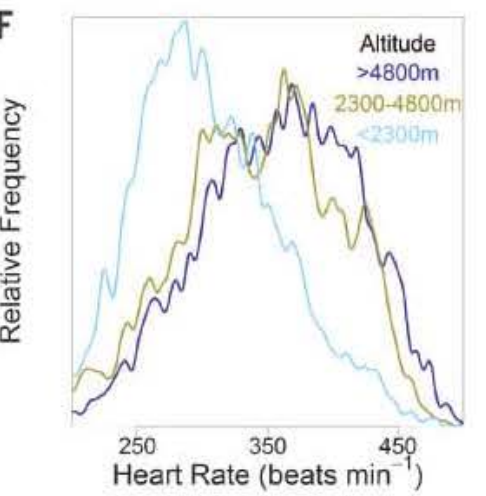

I

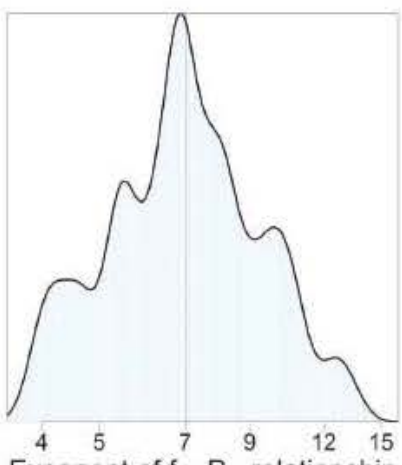

Exponent of $f_{w} \sim P_{m}$ relationship 

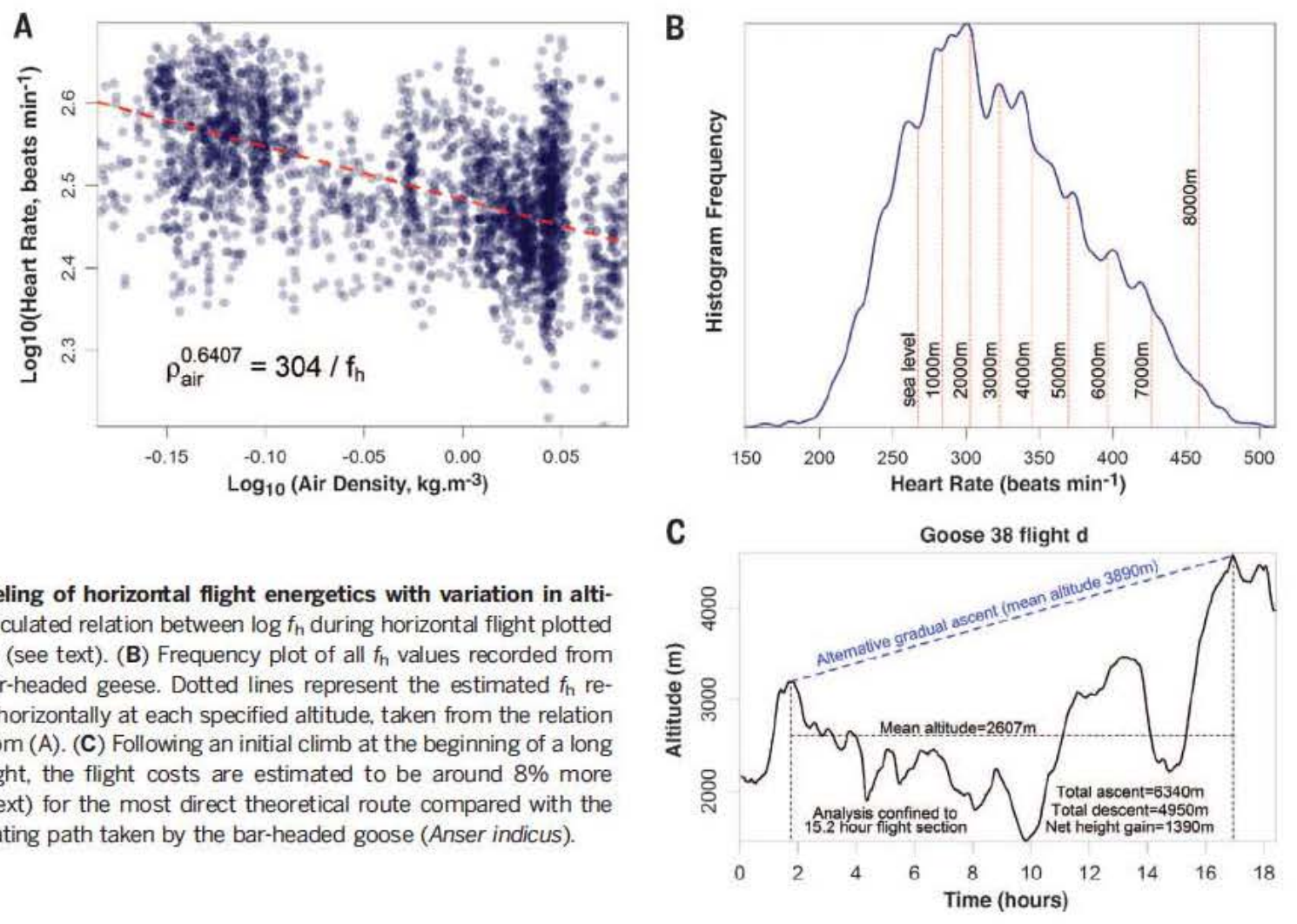

Fig. 3. Modeling of horizontal flight energetics with variation in altitude. (A) Calculated relation between $\log f_{h}$ during horizontal flight plotted against $\log \rho$ (see text). (B) Frequency plot of all $f_{h}$ values recorded from the same bar-headed geese. Dotted lines represent the estimated $f_{\mathrm{h}}$ required to fly horizontally at each specified altitude, taken from the relation calculated from (A). (C) Following an initial climb at the beginning of a long migratory flight, the flight costs are estimated to be around $8 \%$ more costly (see text) for the most direct theoretical route compared with the actual undulating path taken by the bar-headed goose (Anser indicus).

A

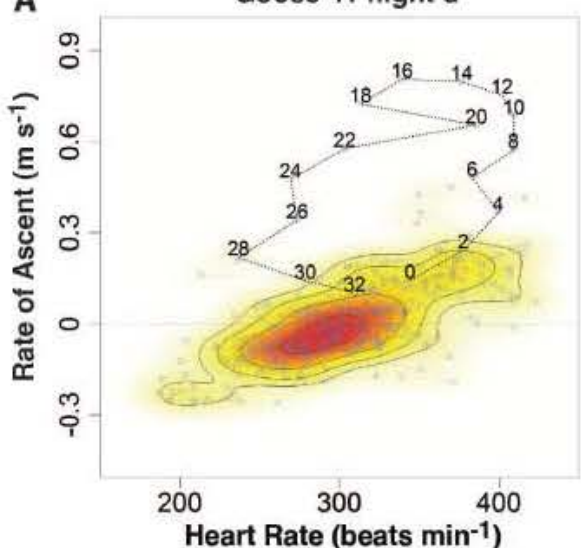

B

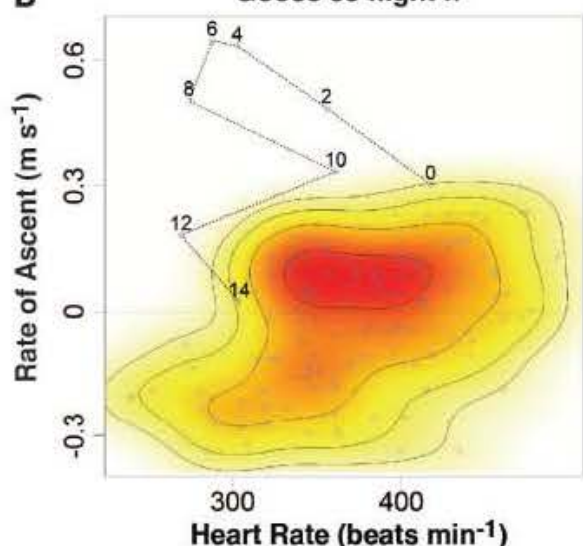

C

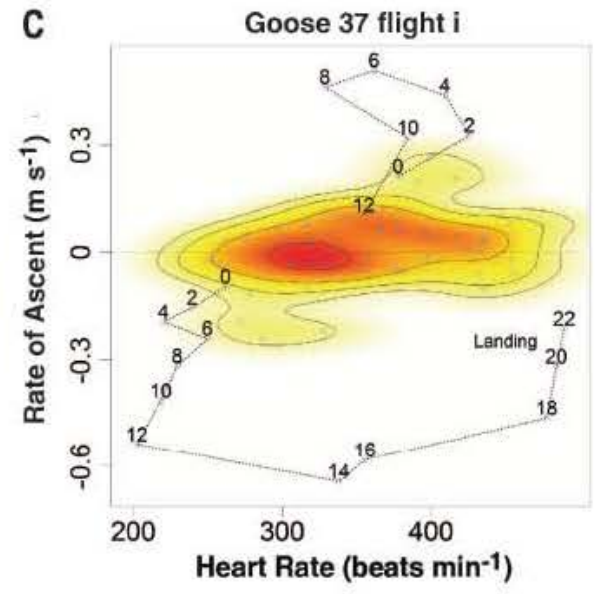

D

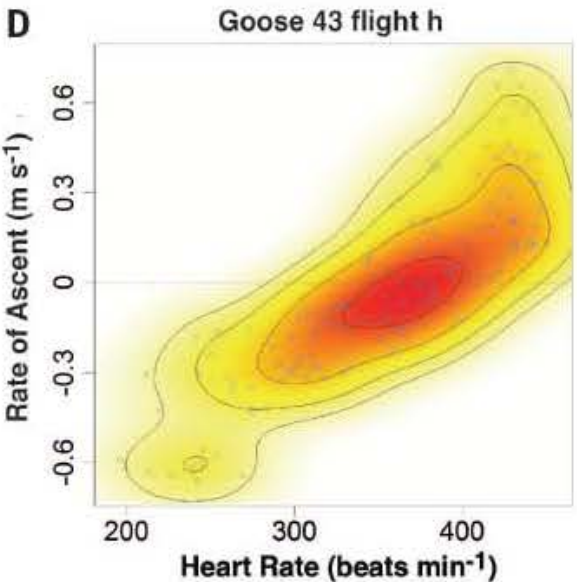

Fig. 4. Environmentally assisted flights. (A to D) Rate of ascent and/or descent plotted against $f_{h}$ for an single migratory flight from four individual Bar-headed geese (Anser indicus). Intensity of color from red to yellow indicates density of observations, with a temporal resolution of $2 \mathrm{~min}$. Black lines link up sequential data points (numbered with time in minutes) to indicate an event lying outside the typical distribution, highlighting periods of assisted lift, along with a single difficult landing event in (C). 
costs of flapping the wings should be propor tional to the product of wingbeat frequency cubed and the wing amplitude squared. If the body of the bird undergoes sinusoidal ampli tude displacements on the vertical axis $(B)$ then $\ddot{Z}_{\mathrm{rms}}^{2}=2 \sqrt{ } 2 \pi^{2} B f_{\mathrm{w}}{ }^{2}(22)$ and so Eq. 2 can be rewritten

$$
P_{\mathrm{b}}=4 \pi^{2} B^{2} f_{\mathrm{w}}^{3}(3) .
$$

Because $B$ should be positively correlated with wingbeat amplitude, the implication of our experimental data, showing that $P_{\mathrm{m}} \propto f_{\mathrm{w}}{ }^{6.96}$, is that the angular travel of the wing increases with higher $f_{\mathrm{w}}$. Thus, the exquisite sensitivity of $P_{\mathrm{m}}$ to $f_{\mathrm{w}}$ in geese stems from wingbeat am plitude that is positively correlated with changes in wingbeat frequency.

In the present study, there was no evidence of gliding behavior in bar headed geese, even when descending rapidly from the Himalayas into India (fig. S4). During the steepest de scent phases, $f_{\mathrm{w}}$ remained above $3.6 \mathrm{~Hz}$ for $98 \%$ of observations, whereas $f_{\mathrm{h}}$ decreased to be tween 150 and 200 beats $\min ^{-1}$. Indeed, $f_{\mathrm{h}}$ was surprisingly low in general throughout the entire migration (overall mean $f_{\mathrm{h}}=328+$ 64 beats $\mathrm{min}^{-1}$ ) (Fig. 2F), with geese only spend ing $2.3 \%$ of their flight time at altitudes above $4800 \mathrm{~m}$ with a $f_{\mathrm{h}}$ greater than 455 beats $\mathrm{min}^{-1}$ (and $0.37 \%$ of their flight time when below $2300 \mathrm{~m}$ altitude). A simple extrapolation of the relations between heart rate and air density (Fig. 3A), with data filtered so that only rates of ascent or descent lying between $+0.1 \mathrm{~m} \mathrm{~s}^{-1}$ are included (an approximation of horizontal flight), demonstrates that a minimum heart rate of around 460 beats min $^{-1}$ might just suf fice at around $8000 \mathrm{~m}$ in still air conditions (Fig. 3B). However, even this assessment might seem unduly optimistic, given that it ignores the energetics and time required to make the climb itself and the steepness of the relation for hemoglobin desaturation once the partial pres sures of oxygen fall below a critical value $(18,23)$. Thus, unaided horizontal flights over $8000 \mathrm{~m}$ are likely to be approaching the limit for sus tained aerobic capacity in this species.

Previous low temporal resolution global po sitioning system altitude data (12) indicated that bar headed geese tend to fly closest to the ground when traversing the Tibetan massif, with a median height of only $62 \mathrm{~m}$. This is con sistent with the high resolution pressure alti tude results of the present study, which imply that geese opt repeatedly to shed hard won al titude only subsequently to regain height later in the same flight. An example of this tactic can be seen in a 15.2 hour section of a 17 hour flight (Fig. 3C) in which, after an initial climb to $3200 \mathrm{~m}$, the goose followed an undulating profile involving a total ascent of $6340 \mathrm{~m}$ with a total descent of $4950 \mathrm{~m}$ for a net altitude gain of only $1390 \mathrm{~m}$. Revealingly, calculations show that steadily ascending in a straight line would have increased the journey cost by around $8 \%$. As even horizontal flapping flight is relatively ex pensive, the increase in energy consumption due to occasional climbs is not as important as the effect of reducing the general costs of flying by seeking higher density air at lower altitudes.

Rates of ascent and descent during four migratory flights are plotted against $f_{\mathrm{h}}$ (Fig. 4) and against $f_{\mathrm{w}}$ (fig. S5), with maximum ascent rates of up to at least $0.8 \mathrm{~m} \mathrm{~s}^{-1}$, lasting for sev eral minutes. However, such extreme ascent rates were generally not associated with in creases in $f_{\mathrm{h}}$ and $f_{\mathrm{w}}$. A particularly clear ex ample of such an episode that occurred during a 13 hour migratory flight is shown in Fig. 4A. The central cluster of Fig. 4A exhibits a sloping relation between $f_{\mathrm{h}}$ and rate of ascent (typical of a number of flights), but there was a dramatic departure from this pattern lasting $\sim 30 \mathrm{~min}$ in volving unusually high rates of ascent despite "normal" values of heart rate. Although the de gree of central clustering varied between flights, presumably according to the prevailing wind conditions and underlying terrain, similar un usually high ascent rates occurred on other flights (Fig. 4, B to D). These unique results are interpreted as evidence of sustained as sistance from updrafts due to orographic lift $(27,28)$, presumably indicative of geese flying along the windward side of a ridge. Thus, it is logical to conclude that weaker vertical updrafts could also provide more gentle assistance during other phases of the migratory flights, perhaps comparable in magnitude to the assistance geese might at times receive from $\mathrm{V}$ formation flight $(29,30)$.

When traversing mountainous areas, a terrain tracking strategy or flying in the cool of the night (12) can reduce the cost of flight in bar headed geese through exposure to higher air density. Ground hugging flight may also confer additional advantages including maximizing the potential of any available updrafts of air, reduced expo sure to crosswinds and headwinds, greater safety through improved ground visibility, and increased landing opportunities. The atmospheric challenges encountered at the very highest alti tudes, coupled with the need for near maximal physical performance in such conditions, likely explains why bar headed geese rarely fly close to their altitude ceiling, typically remaining below $6000 \mathrm{~m}$. Given that aerodynamic mass specific flight costs are thought to increase with body mass and that bar headed geese are heavier than $98 \%$ of avian species, it is partic ularly impressive that these birds are able to migrate across the world's highest land massif while remaining comfortably within their phys iological capabilities.

\section{REFERENCES AND NOTES}

1. H. Schmaljohann, F. Liechti, B. Bruderer, Proc. Biol. Sci. 274, 735739 (2007).

2. R. H. G. Klaassen, T. Alerstam, P. Carlsson, J. W. Fox, A. Lindström, Biol. Lett. 7, 833835 (2011).

3. P. J. Butler, A. J. Woakes, C. M. Bishop, J. Avian Biol. 29, 536545 (1998).

4. S. A. Shaffer et al., Proc. Natl. Acad. Sci. U.S.A. 103, 1279912802 (2006).
5. R. E Gill Ir et al., Proc. Biol. Sci. 276, 447457 (2009).

6. L. A. Hawkes et al., Proc. Natl. Acad. Sci. U.S.A. 108 95169519 (2011)

7. A. Blum, Annapurna: A Woman's Place (Sierra Club, San Francisco, 1998).

8. L. W. Swan, Nat. Hist. 70, 6875 (1970)

9. F. M. Faraci, Annu. Rev. Physiol. 53, 5970 (1991).

10. G. R. Scott, W. K. Milsom, Respir. Physiol. Neurobiol. 154 284301 (2006)

11. B. Pinshow, M. H. Bernstein, Z. Arad, Am. J. Physiol. 249 R758 R764 (1985).

12. L. A. Hawkes et al., Proc. Biol. Sci. 280, 20122114 (2013).

13. R. J. Spivey, C. M. Bishop, Rev. Sci. Instrum. 85, 014301 (2014).

14. C. M. Bishop, R. J. Spivey, J. Theor. Biol. 323, 1119 (2013)

15. P. J. Butler, J. A. Green, I. L. Boyd, J. R. Speakman, Funct. Ecol. 18, 168183 (2004).

16. J. A. Green, Comp. Biochem. Physiol. A Mol. Integr. Physiol. 158, 287304 (2011).

17. S. Ward, C. M. Bishop, A. J. Woakes, P. J. Butler, J. Exp. Biol. 205, 33473356 (2002).

18. L. A. Hawkes et al., PLOS ONE 9, e94015 (2014).

19. L. G. Halsey, S. J. Portugal, J. A. Smith, C. P. Murn, R. P. Wilson, J. Field Ornithol. 80, 171177 (2009).

20. K. H. Elliott, M. Le Vaillant, A. Kato, J. R. Speakman, Y. Ropert Coudert, Biol. Lett. 9, 20120919 (2013).

21. O. Duriez et al., PLOS ONE 9, e84887 (2014).

22. R. J. Spivey, C. M. Bishop, J. R. Soc. Interface 10, 20130404 (2013).

23. J. U. Meir, W. K. Milsom, J. Exp. Biol. 216, 21722175 (2013).

24. C. Pennycuick, J. Exp. Biol. 199, 16131618 (1996).

25. F. Liechti, E. Schaller, Naturwissenschaften 86, 549551 (1999).

26. R. J. Spivey, S. Stansfield, C. M. Bishop, Prog. Oceanogr. 125, 6273 (2014)

27. P. J. Butler, Comp. Biochem. Physiol. A Mol. Integr. Physiol. 156, 325329 (2010).

28. G. Bohrer et al., Ecol. Lett. 15, 96103 (2012).

29. H. Weimerskirch, J. Martin, Y. Clerquin, P. Alexandre, S. Jiraskova, Nature 413, 697698 (2001).

30. S. J. Portugal et al., Nature 505, 399402 (2014).

\section{ACKNOWLEDGMENTS}

The work was conducted with permission from the Mongolian Academy of Sciences and the Wildlife Science and Conservation Centre. Primary funding was from a UK Biotechnology and Biological Sciences Research Council (BBSRC) award to C.M.B. and P.J.B. (grant no. BB/F015615/1) and a Natural Sciences and Engineering Research Council of Canada award to W.K.M., with additional support from the Max Planck Institute for Ornithology, the U.S. Geological Survey, Western Ecological and Patuxent Wildlife Research Centers, Avian Influenza Programme, and the FAO through the Animal Health Service EMPRES surveillance program. We are grateful to the support of all the field team members in Mongolia, to A. Davies for developing the first generation of heart rate data loggers, and to the work of Beaumaris Instruments Ltd. in the development of housings for the instruments. Thanks also to S. Ward for providing the wind tunnel heart rate calibration data. The use of trade names in this document is for descriptive purposes only and does not imply endorsement by the U.S. government. Links to the data presented in the figures are provided in the supplementary materials. Author contributions. C.M.B. and P.J.B. led the study. C.M.B., P.J.B., L.A.H., N.B., W.K.M, G.R.S, J.Y.T., S.H.N., P.B.F., and M.W. conceived and/or designed the fieldwork. B.C. led and conducted the veterinary work, with assistance from the field team. N.B., L.A.H., T.N., C.M.B., G.R.S, and J.Y.T. conducted the fieldwork. C.M.B. and R.J.S. wrote the paper, which was then reviewed by all authors. R.J.S. designed the instruments, analyzed the data collected and generated the figures, in consultation with C.M.B. 